\title{
Whole-region Tourism Greenway Network Organization Mechanism Based on Gravity Model Flow Measurement
}

\begin{abstract}
Xue JIANG, School of Architecture, Harbin Institute of Technology; Key Laboratory of Cold Region Urban and Rural Human Settlement Environment Science and Technology, Ministry of Industry and Information Technology; China

Tianyu ZHAO; School of Architecture, Harbin Institute of Technology; Key Laboratory of Cold Region Urban and Rural Human Settlement Environment Science and Technology, Ministry of Industry and Information Technology; China
\end{abstract}

\begin{abstract}
The structure and organization of greenway network is the core stone of greenway planning. Generally, the relevant between point elements and line elements in the network is taken as the focus of quantitative structure evaluation. In this study, the evaluation and organization method of greenway network is based on gravity model flow measurement. Ningan city is taken as an example because of its rich tourism resources and ecological resources. The cost distance formula has been improved in the process. Network flow is allocated to each path in the gravitational model to enhance the scientific evaluation. Firstly, the existing greenway network structure is sorted out and summarized. Minimum cost path method is used to form potential greenway network structure. This structure is divided into two parts, one is based on comprehensive elements and the other is based on general elements. The existing structure and potential structure are combined to form a preliminary abstract network structure. Gravity model is used to measure and classify the traffic among abstract network nodes. Two kinds of greenway network structures are compared and analyzed. On this basis, the greenway network is optimized and verified through field research. It provides a basis for the further planning and implementation of the actual greenway network in small towns
\end{abstract}

\section{Keywords}

small town planning, greenway network, Whole-region tourism, gravity model, flow measurement

\section{Introduction}

Greenway construction and development has entered a relatively rapid stage of development in China since 2010. It is an inevitable trend for the networking of greenways. In the rapid construction of Greenway network, more attention should be paid to the construction of greenway network structure. The quantification of greenway network planning and construction is of great significance to the scientific construction of greenway system. 
At present, the organization methods of greenway network are mostly based on graph theory, Euclidean distance, connectivity and probability theory. It is neglected for the bearing capacity of the elements themselves and the flow rate of the line elements. Meanwhile, China's Whole-region tourism has developed rapidly since 2016. For the greenway of small tourism towns, the carrying capacity of greenway needs to be further considered the impact of leisure tourism. Taking the above factors into account, the view of flow and demand is put forward as the function synthesis in the construction of greenway structure, so as to meet the planning and development of greenway network in small tourism towns.

\section{Analysis of existing greenway network structure in Ningan}

\subsection{Research Background}

Located in the southeast of Heilongjiang Province, Ningan is famous for Jingbo Lake Tourism Scenic Area (Fig.1). From 2012, the rapid development of tourism industry has also led to the development of tertiary industry. By 2017, a total of 1.77 million visitors were received, with an annual increase of $26.1 \%$.

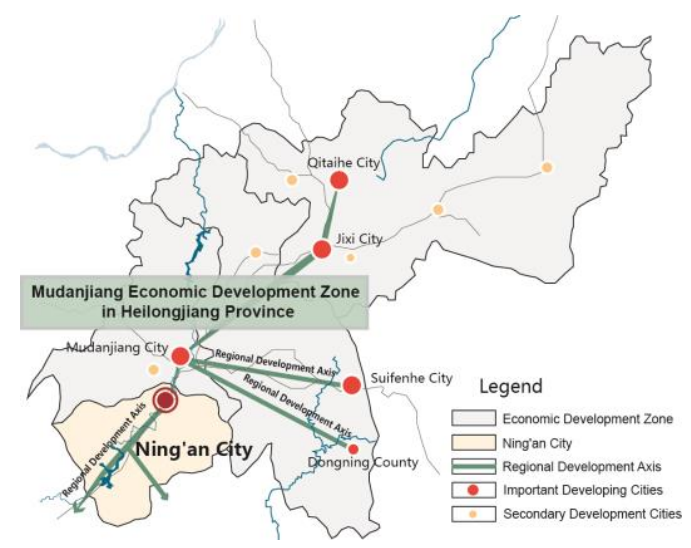

Figure 1 Distribution of major resources in Ningan City

\section{Figure sources: drawn by author}

There are abundant resources and various land use types in Ningan. The types of tourism resources are comprehensive, covering eight categories in the Classified Investigation and Evaluation of Tourism Resources (GBT18972-2003). There are 3 nature reserves, 4 ecological townships and 25 Provincial Ecological Villages in the city. The main ecological resources include characteristic water resources such as Jingbo Lake and Mudanjiang River, abundant mountain forest resources and various agricultural resources. They have all kinds of resource bases for developing greenway network from the perspective of Whole-region tourism.

\subsection{Element Screening of Greenway Network}

Taking the Whole-region tourism service value as the evaluation index, combining with national standards, provincial and municipal standards, village and town standards, Ningan's Whole-region resources of ecology, humanities, industry and recreation were screened through field research. 
A total of 24 green paths and 23 important resource nodes were screened out (Fig.2).

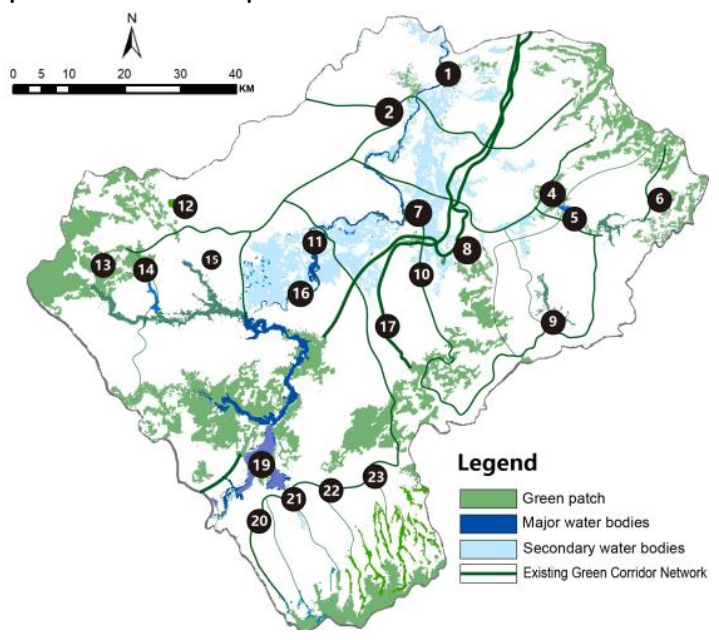

Figure 2 Green path and node distribution

\section{Figure sources: drawn by author}

(1) Green corridor: From the spatial distribution, most of the corridors are distributed along major rivers, large lakes and mountains, especially along the vertical green corridor along the Mudan River and Jingbo Lake, as well as the horizontal green corridor along the Mudan River and Xiaobeihu Lake, which constitute the main framework of the existing green corridor in Ningan City. On the west side of the city, a small-scale greenway network with Jingbo Lake Scenic Area as the core has been formed, which combines the surrounding woodland, park green space and so on. In the southeast of the city, large areas of woodland, cultivated land and types of green space are relatively dense. The main roads and railways with vertical distribution in the city are regarded as the main axle belts for the development of green industry. It forms a green channel for industry, and there are many alternative paths in the process of connecting and spreading with other patches in the city. Due to the dispersed distribution of green patches and the absence of a system of existing greenways, the tourism greenway network is divided into five parts scattered in the city. The network connection is not close enough to activate the overall greenway network to play the role of sustaining the benefits of leisure economy and ecological vitality.

(2) Important resource nodes: Important resource nodes are mainly divided into recreational resource nodes, humanistic resource nodes, ecological and industrial resource nodes. Important resource nodes are distributed along the north-south axis and east-west axis of the city as a whole. Because urban settlements play an important role in the Whole-region tourism development of the greenway network, in order to make the formed greenway network benefit more urban residents, strengthen the participation and utilization of the greenway network, urban settlements are listed as the secondary nodes of the network and the important priority choice of network intersection nodes. In addition, the distribution of forestry resources in Ningan has formed its ecological environment matrix, and forestry resources can be used as node resources in the development of tourism to analyse its role in promoting Whole-region tourism. With the further development of forestry resources combined with leisure trails and eco-tourism, a large area of forestry green patches will become the basis of the development of the tertiary industry. Therefore, important forest farm resources are extracted in the form of node resources, so as to facilitate the pertinence and implementation of subsequent planning. 


\subsection{Existing abstract structure of Greenway Network}

\section{(1) Abstraction and analysis of current network corridors}

In order to analyse the present situation and future structure of greenway network more clearly and clearly, the existing elements are abstracted to form the abstract structure of Greenway network. The network corridor between resource nodes is connected according to the degree of close connection between traffic function, landscape function and ecological function.

Through the abstract results, there are 109 corridors in the existing greenway network, connecting 81 nodes (Fig.3).

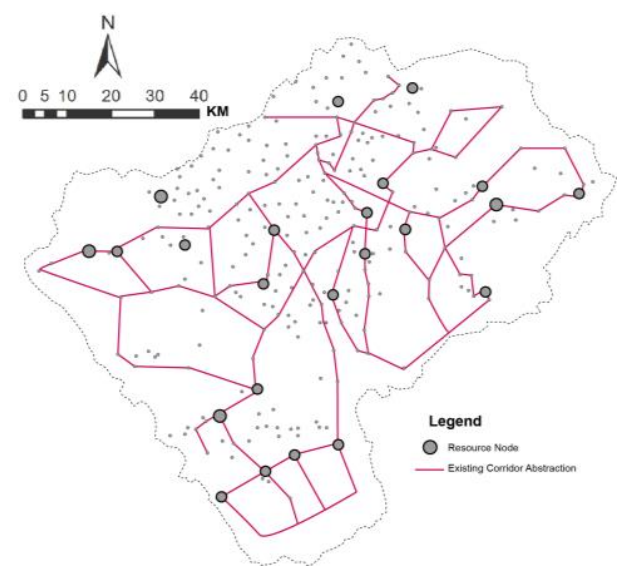

Figure 3 Analysis of network node factor domination area

\section{Figure sources: drawn by author}

At present, four key resource points are not connected into the network by corridors. The aindex of existing networks is 0.18 . It shows that the number of loops in the corridor network is relatively small, which makes the greenway network show the characteristics of higher linear connection and lower replacement connection. The $\beta$ index of network corridor is 1.35. It shows a lower level. It shows that the existing greenway network nodes have the problems of relative isolation, punctuation and smoothness. The network corridor $\gamma$ index is 0.46. It shows that the network connectivity of the whole network structure is not strong. It does not form a relatively effective connection channel. The main reason for the characteristics of the network corridor is the lack of overall planning for the greenway network in the development of the county and municipality. Urban landscape fragmentation has been aggravated. The effective connections of Greenway nodes are gradually reduced.

\section{(2) Streamlining and analysis of current network structure}

Through actual investigation, the corridor structure is simplified and reorganized according to the logical relationship (Fig. 4). The current network structure includes 23 network nodes and 30 network corridors. According to the importance of resources, it can be divided into primary network, secondary network and tertiary network. Among them, the primary network structure is used as the basis of network construction. Ningan city's important tourism resources and ecological resources are connected by the first-level network. It is the main network skeleton at present. Major residential areas, industrial parks and Jingbo Lake scenic spots are connected in the North-South direction. It extends to the west to connect the Xiaobeihu scenic area and to the east to connect the birch River Scenic area. The 
secondary network structure is regarded as the connectivity and perfection of the primary network. The three-level network mainly reflects the contact line at the site level. At present, it is not perfect, and cannot play a good role in expanding the network. It needs to be further optimized and upgraded.

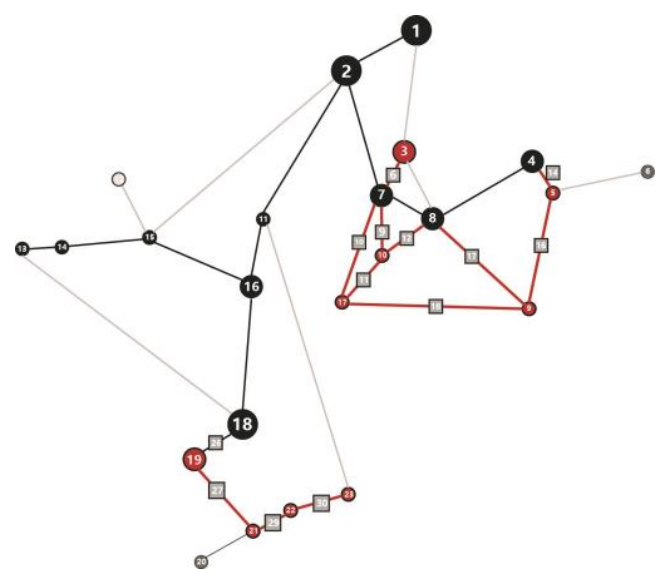

Figure 4 Existing abstract network structure

Figure sources: drawn by author

\section{Network traffic measurement based on Gravity Model}

\subsection{Factor Resistance Value Assignment}

In the measurement of network traffic, the interaction force between the elements of each node is determined by gravitational model. Firstly, the resistance value assignment of each factor needs to be determined in the flow measurement ${ }^{[6]}{ }^{[9]}$. In order to compare and analyse the differences of Whole-region tourism greenway network schemes, two comparative structures were proposed based on the differences of comparative corridors when Whole-region tourism integration was included or not accepted.

Firstly, each factor is assigned according to the influence degree of Whole-region tourism resistance (Fig.5) . It integrates three factors to be judged and calculated, including resource type, vegetation coverage and tourism sensitivity. Because of the emphasis of this study on the Whole-region tourism impact, the proportion of resource types is 0.35 , the vegetation coverage is 0.20 , and the tourism sensitivity is 0.45 . The comprehensive resistance of Whole-region tourism reflects the difficulty of energy flowing between different node units, including "ecology, production and life". In the greenway network organization based on general basic elements, only resource type resistance and vegetation coverage resistance are considered. In this case, the proportion of resource types is 0.64 and the vegetation coverage is 0.36 . 


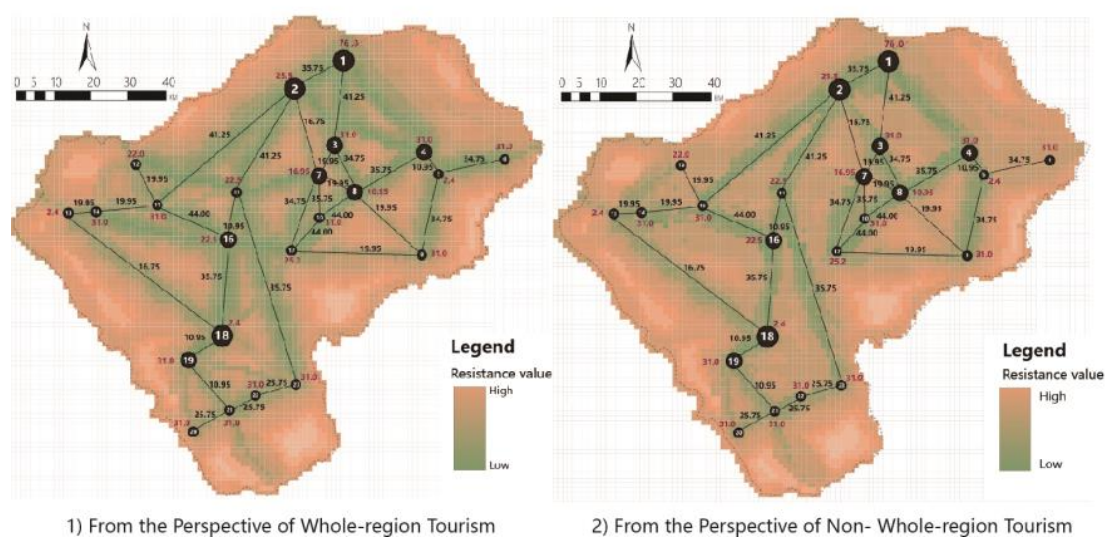

Figure 5 Comparison of two cumulative cost surface

\section{Figure sources: drawn by author}

\subsection{Flow Measurement}

The flow measurement formula is improved according to the gravitational formula. Generally, the distance cost between node $i$ and node $j$ is expressed as $D_{i j}=L_{i j} / L_{\max } . L_{i j}$ is the cumulative cost of functions between nodes $I$ and $j$, and the maximum cost of all functions in the $L_{\max }$ research area. In this study, cumulative function cost is regarded as the inverse ratio of the mutual attractiveness between two nodes, that is, the greater the mutual attractiveness between two nodes, the smaller the cumulative function cost (Table 1). Therefore, gravity formula can be defined as $L_{i j}=1 /\left(r^{2} / L_{i} L_{j}\right)=r 2 / L_{i} L_{j}$, which $L_{i}$ and $L_{j}$ are the element resistance values of node $i$ and node $j$ respectively, and $R$ is the minimum distance between node $i$ and node $j$. Therefore, the flow matrix can be generated based on the nodal mutual attractiveness of the comprehensive resistance value of Greenway elements and the resistance value of general elements. Based on the calculation of mutual attractiveness, the traffic among the greenway network nodes is further calculated. Inter-source corridors with high interaction intensity were extracted as main corridors and other potential corridors were supplemented.

Table 1 Cost matrix of attractiveness of abstract greenway network nodes

Data Source: Surveyed and calculated by the author

\begin{tabular}{|c|c|c|c|c|c|c|c|}
\hline 1 & 2 & 3 & 4 & & 21 & 22 & 23 \\
\hline 0 & 0.13 & 0.22 & 0.46 & $\ldots$ & 5.91 & 5.71 & 4.59 \\
\hline 0.13 & 0 & 0.53 & 2.04 & $\ldots$ & 13.16 & 14.67 & 9.77 \\
\hline 0.22 & 0.22 & 0 & 0.88 & $\ldots$ & 11.52 & 12.84 & 14.49 \\
\hline 0.46 & 2.04 & 0.88 & 0 & $\ldots$ & 11.65 & 13.05 & 14.46 \\
\hline$\ldots$ & $\ldots$ & $\ldots$ & $\ldots$ & $\ldots$ & $\ldots$ & $\ldots$ & $\ldots$ \\
\hline 5.91 & 13.16 & 11.52 & 11.65 & $\ldots$ & 0 & 0.07 & 0.41 \\
\hline 5.71 & 14.67 & 12.84 & 13.05 & $\ldots$ & 0.07 & 0 & 0.14 \\
\hline 4.59 & 9.77 & 14.49 & 14.46 & $\ldots$ & 0.41 & 0.14 & 0 \\
\hline
\end{tabular}

\subsection{Measure Result}

The difference of mutual attractiveness among different resource points is taken as an important judgment basis in the extraction of potential greenway structure. However, the resistance value of the Whole-region tourism greenway network is different from that of the general greenway network. In both cases, nodes with mutual attractiveness greater than 
$70 \%$ are structurally connected. It generates two kinds of network structures respectively. The Cumulative Cost Surface is shown in Fig.5. The network structure based on the measured results of network flow can be seen from Fig.6. A-type network structure is extracted from the cumulative cost surface formed from the perspective of Whole-region tourism. The B-type network structure is formed on the basis of the cumulative cost surface from the perspective of non-Whole-region tourism.

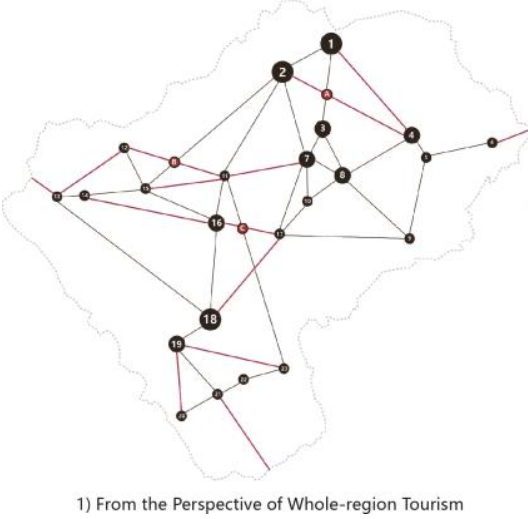

Figure 6 Comparison of two measurement results

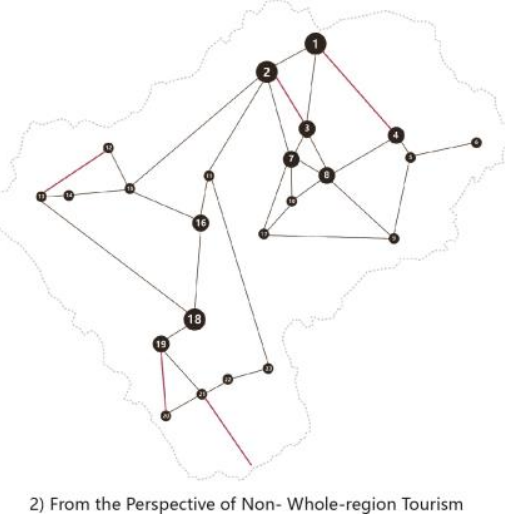

Figure sources: drawn by author

From the result of generation, the potential greenway composition in the network structure based on the resistance value of comprehensive greenway elements is more abundant. More nodes have the possibility of connecting. Nodes related to tourism resources play a more important role, making the construction of the whole greenway network more prominent. The overall structure also has more possibilities to expand to the periphery of the city. The B-type structure lacks certain extensibility. It is weakly connected with the outside of the city. At the same time, its internal potential greenway and the current greenway have a strong consistency. If only the network structure based on general natural ecological factors can not satisfy the further optimization of its network development.

\section{Evaluation and revision of abstract greenway network}

\subsection{Grading calculation of Greenway based on structural optimization}

The greater the attraction between the nodes in the greenway network, the greater the flow between them and the stronger the function of the corridor. For the corridors in this study, there are corridors that can be reused [10]. Therefore, the final cumulative frequency flow of a single corridor is obtained and calculated by superposition of the functional flow of the corridor.

The function flow matrix can be obtained by superimposing the function flow of Greenway connected by different nodes. The higher the flow rate, the higher the frequency of corridors used. In order to make the evaluation results clearer, the functional flow corridors of the greenway network are also divided into three levels in this analysis (Fig. 7). 

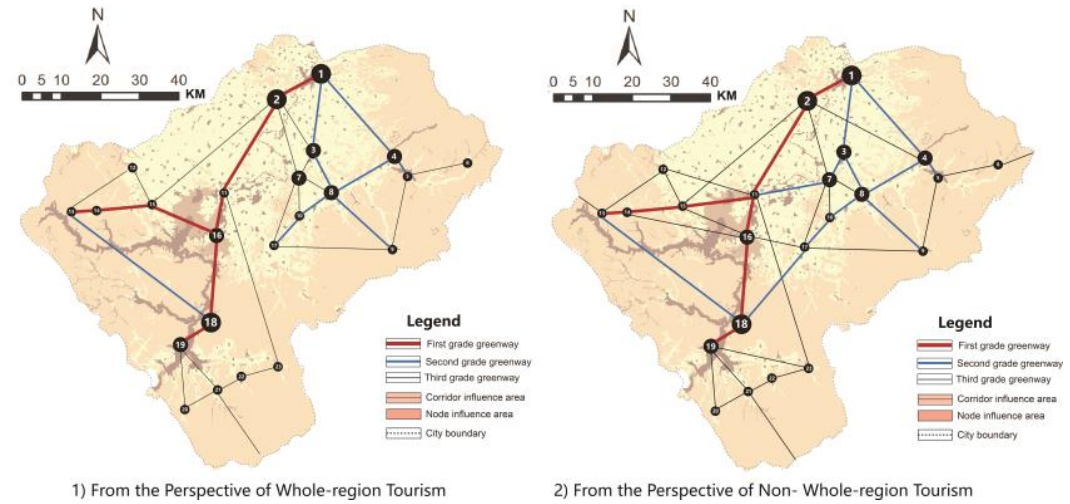

Figure 7 Evaluation chart of corridor comprehensive function flow

\section{Figure sources: drawn by author}

Compared with the existing corridor system, the first-class corridor of A-type structure and B-type structure lays more emphasis on the main line running through the north and south, and the two lines of tourism from the central to the western Jingpo Lake natural scenic spot. Because of the slow development of the eastern part, the functional flow is less. At the same time, more three-level network corridors are formed through the concept of functional flow to avoid the deterioration of the ecological patch island effect in the original network.

Compared with B-type corridor, A-type corridor brings about the improvement of secondary corridor structure based on the integration of forest farms, reservoirs and farms with the development of Whole-region tourism. Secondary function flow is no longer only concentrated in the eastern and central part of Ningan, but based on the eastern and central part of Ningan. It runs through the whole network framework and plays a transitional role of better connection between the first-level corridor and the third-level corridor. In the eastcentral part, the radiation structure is formed with Huashuchuan Reservoir Nature Reserve as the core. In the west, the secondary functional flow corridor connects Xiaobeihu Nature Reserve and Jingbo Lake Nature Reserve, which makes all the important tourism, production and living nodes in Ningan City connect in an orderly way. Therefore, the structure of the Whole-region tourism function corridor has certain operability and structure optimization ability.

\subsection{Greenway Network Certification Based on Field Research}

The revision of the greenway network structure mainly considers two aspects: the coverage of the network and the possibility of the actual formation of the network. First, the greenway network should basically cover all existing residential areas and tourist areas, so as to promote the development of Whole-region tourism more efficiently. Secondly, the construction of greenway network is closely related to the production and life of citizens. After the construction and evaluation based on theory, the possibility of network formation is determined through field research, and some of its structures are renovated to ensure the reliability and validity of the greenway network architecture.

The influence area of the greenway is generally buffered by 15 minutes' walking, cycling and driving distance outside the corridor and nodes ${ }^{[1]}$. This buffer is a more convenient and frequently used area for its node and corridor accessibility. From the perspective of Wholeregion tourism, the influence scope of Greenway should be expanded correspondingly because of the scale benefit brought by tourism. According to the relevant requirements of 
the National Garden City standard, the service radius of general park green space is $\mathbf{5 0 0}$ meters. However, due to the large spacing of urban resource points and the lower degree of resource concentration compared with cities, the service and impact capacity of patches in the greenway network in this study are affected by many factors. According to the field survey results of 500 residents in the city, residents within 10 kilometres from the resource point are all positively affected by the resource point (Fig.8). Therefore, combined with relevant research, the influence range of primary corridor is $10 \mathrm{~km}$, secondary corridor is 5 $\mathrm{km}$ and the tertiary corridor is $2.5 \mathrm{~km}$.

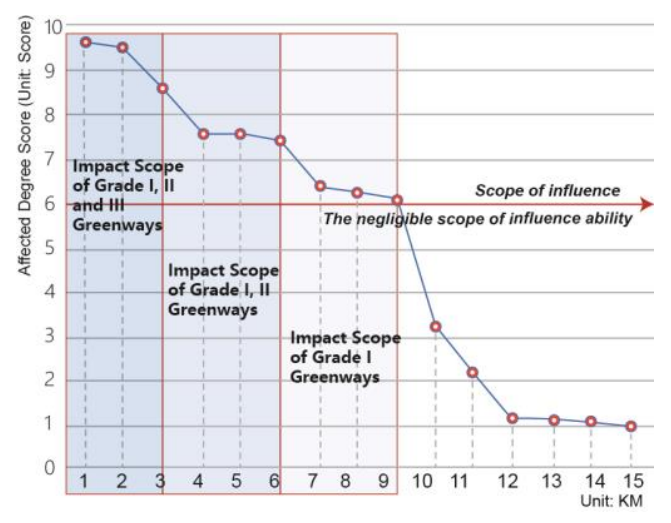

Figure 8 Resource point impact scope survey

\section{Figure sources: drawn by author}

According to the overall situation of the current greenway network structure coverage (Fig.9), type A based on the Whole-region tourism perspective has certain structural advantages. Firstly, compared with the current situation, the greenway network structure has more balanced coverage for the whole city. It breaks the current situation of relying on the western side of the city mirror Lake Scenic Area of the single focus of development. Two new development cores have been formed on the East and south sides of the city area, and the multi-level structure has been expanded outward depending on the original trend of the first-level network. Secondly, compared with B-type network structure, the density of secondary corridor and tertiary corridor of A-type network is higher, the influence scope of the whole network is wider and the connection between different levels of network is smoother.
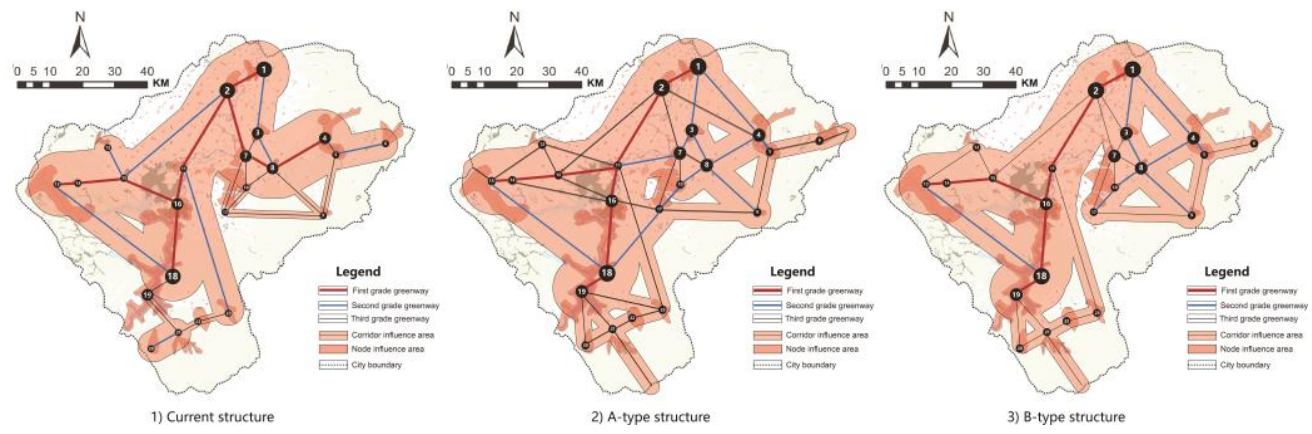

Figure 9 Greenway network structure coverage area

Figure sources: drawn by author

However, as far as the structure of the current A-type network itself is concerned, there is still room for further optimization. First of all, the third level corridor structure can still 
further cover the southwest side of the city. The network structure makes insufficient use of forest farms on the southern side of the city. According to the field investigation, the threelevel corridors on the southeast side of the city can be further improved, mainly the possibility of connection between 6,9 and 23 corridors, and the possibility of connection between 1 and 6 corridors on the northeast side of the city. Secondly, the primary corridor composed of nodes $1,2,7,8$ and 4 is not reflected in the A-type structure, mainly because the mutual attraction between patches is relatively weak from the perspective of Wholeregion development. However, according to the field investigation, the possibility of the formation of the first-class corridor in the west can be further explored, so as to improve the first-class corridor structure in the A-type structure.

Important nodes in primary and secondary networks are mainly investigated. A questionnaire survey and interviews were conducted among 500 citizens and tourists (Table 2). The network certification work was carried out in combination with the opinions of six planning experts. Questionnaire is mainly about the way of scoring between two nodes in the existing structure and corridors with certain possibilities in the above analysis.

Table 2 Survey Scores for the possibility of corridor formation in type A structure

Data Source: Surveyed and calculated by the author

\begin{tabular}{|c|c|c|c|c|c|c|c|}
\hline classification & number & $\begin{array}{l}\text { Resident } \\
\text { Score }\end{array}$ & $\begin{array}{c}\text { Tourist } \\
\text { Score }\end{array}$ & $\begin{array}{l}\text { Expert } \\
\text { Score }\end{array}$ & $\begin{array}{c}\text { Comprehen } \\
\text { sive score }\end{array}$ & Grade & $\begin{array}{l}\text { Modif- } \\
\text { ication }\end{array}$ \\
\hline \multirow{28}{*}{$\begin{array}{l}\text { A-type } \\
\text { structure } \\
\text { corridor }\end{array}$} & L1-2 & 8.5 & 7.5 & 8.5 & 8.17 & first & $x$ \\
\hline & L1-3 & 7.5 & 7.5 & 9.0 & 8.00 & first & $\mathrm{v}$ \\
\hline & L1-4 & 6.5 & 7.5 & 7.0 & 7.00 & Second & $x$ \\
\hline & L2-4 & 6.0 & 7.0 & 6.5 & 6.50 & Third & $x$ \\
\hline & L2-7 & 5.5 & 7.5 & 7.0 & 6.67 & Third & $x$ \\
\hline & L2-11 & 9.5 & 7.5 & 8.5 & 8.50 & first & $x$ \\
\hline & L2-15 & 6.5 & 7.5 & 6.5 & 6.83 & Third & $x$ \\
\hline & L3-7 & 8.5 & 6.5 & 7.5 & 7.50 & Second & $x$ \\
\hline & L3-8 & 9.0 & 8.5 & 8.5 & 8.67 & first & $v$ \\
\hline & L4-5 & 8.5 & 6.5 & 8.5 & 7.83 & Second & $x$ \\
\hline & L4-8 & 8.5 & 7.5 & 8.0 & 8.00 & first & $\mathrm{v}$ \\
\hline & L5-6 & 5.5 & 6.5 & 6.5 & 6.17 & Third & $x$ \\
\hline & L5-9 & 7.5 & 6.5 & 6.5 & 6.83 & Third & $x$ \\
\hline & L7-8 & 6.5 & 7.5 & 6.5 & 6.83 & Third & $x$ \\
\hline & L7-10 & 7.5 & 6.5 & 6.0 & 6.67 & Third & $x$ \\
\hline & L7-11 & 7.5 & 6.5 & 7.5 & 7.17 & Second & $x$ \\
\hline & L7-17 & 7.5 & 6.0 & 6.5 & 6.67 & Third & $x$ \\
\hline & L8-9 & 7.0 & 7.5 & 8.5 & 7.67 & Second & $x$ \\
\hline & L8-10 & 6.5 & 8.0 & 7.5 & 7.33 & Second & $x$ \\
\hline & L9-17 & 5.5 & 6.5 & 6.5 & 6.17 & Third & $x$ \\
\hline & L10-17 & 7.5 & 6.5 & 7.5 & 7.17 & Second & $x$ \\
\hline & L11-12 & 6.5 & 6.5 & 7.0 & 6.67 & Third & $x$ \\
\hline & L11-15 & 6.5 & 8.5 & 9.0 & 8.00 & first & $x$ \\
\hline & L11-16 & 7.5 & 8.5 & 8.5 & 8.17 & first & $x$ \\
\hline & L12-13 & 6.5 & 6.5 & 7.5 & 6.83 & Third & $x$ \\
\hline & L12-15 & 6.0 & 6.5 & 6.5 & 6.33 & Third & $x$ \\
\hline & L13-14 & 8.5 & 7.5 & 8.5 & 8.17 & first & $x$ \\
\hline & L13-18 & 6.5 & 7.5 & 7.5 & 7.17 & Second & $x$ \\
\hline
\end{tabular}




\begin{tabular}{|c|c|c|c|c|c|c|c|}
\hline & L14-15 & 7.0 & 8.5 & 8.5 & 8.00 & first & $x$ \\
\hline & L14-16 & 6.5 & 6.5 & 7.5 & 6.83 & Third & $x$ \\
\hline & L15-16 & 6.5 & 7.5 & 7.5 & 7.17 & Second & $\mathrm{V}$ \\
\hline & L16-17 & 7.0 & 7.0 & 7.0 & 7.00 & Second & $\mathrm{V}$ \\
\hline & L16-18 & 7.5 & 9.0 & 8.5 & 8.33 & first & $x$ \\
\hline & L17-18 & 7.0 & 8.0 & 7.0 & 7.33 & Second & $x$ \\
\hline & L18-19 & 8.5 & 8.5 & 8 & 8.33 & first & $x$ \\
\hline & L19-20 & 5.5 & 6.5 & 7.0 & 6.33 & Third & $\bar{x}$ \\
\hline & L19-21 & 6.0 & 6.5 & 7.5 & 6.67 & Third & $x$ \\
\hline & L19-23 & 5.5 & 6.0 & 6.5 & 6.00 & Third & $x$ \\
\hline & L20-21 & 6.5 & 6.5 & 6.5 & 6.50 & Third & $\times$ \\
\hline & L21-22 & 6.5 & 6.5 & 7.0 & 6.67 & Third & $x$ \\
\hline & L22-23 & 6.5 & 6.5 & 7.0 & 6.67 & Third & $\times$ \\
\hline \multirow{3}{*}{$\begin{array}{c}\text { Other } \\
\text { Potential } \\
\text { Structural } \\
\text { Corridors }\end{array}$} & L1-6 & 5.5 & 6.5 & 7.0 & 6.33 & Third & $\mathrm{V}$ \\
\hline & L6-9 & 6.0 & 6.5 & 6.5 & 6.33 & Third & $\mathrm{V}$ \\
\hline & L9-23 & 5.5 & 6.0 & 6.5 & 6.00 & Third & v \\
\hline
\end{tabular}

The total score of the questionnaire is 10. A score of more than 6 points is the basis for the formation of corridors. A score of more than 8 points or 7 points is the basis for the formation of a first-class corridor and a second-class corridor. From the evaluation results, synthesizing various opinions, it is possible to form corridors between nodes 6,9 and 23 between nodes 1 and 6 . The original first-class corridor in the west can be further extended. Accordingly, the final structure of Ningan Greenway Network is formed. The GIS tool is used to simulate the greenway, combining with the network structure (Fig. 10).
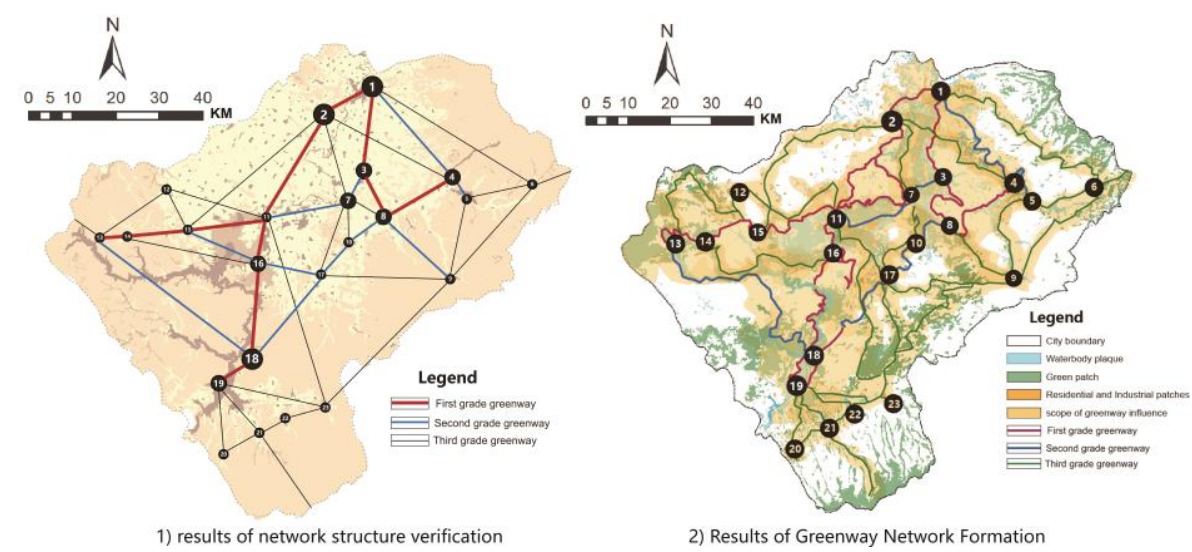

Figure 10 Network structure revision and greenway network formation results

Figure sources: drawn by author

\section{Conclusion}

The comprehensive construction of greenway network organized from the perspective of Whole-region tourism reflects the basic demands of the comprehensive resources' endowment of regional greenway network and the comprehensive promotion of the integration of greenway network resources. The construction of greenway network structure based on gravity model studies the idea of resource flow allocation through network in the evaluation of corridors. It embodies the mutual attraction of elements and explores the 
source corridor with strong interaction as the main corridor. This study obtains a more scientific greenway structure based on traffic measurement, and makes a comparative analysis of the two types of network structure from the perspective of Whole-region tourism. It determines that the overall planning of resources is the optimal path for the network development of Greenway system. Through the research, the influence scope of Greenway at all levels in the Whole-region tourism greenway network is determined, and the actual form of greenway network is formed with the help of GIS. It lays a foundation for the construction and actual construction of county and municipal greenway network.

\section{References}

Binyi Liu. Evolution of urban and rural greenways and their key role in urban greening [J]. Landscape Architecture, 2012 (3): 62-65.

Xiaolong Zhao, Jingran Xu, Bo zhang. Study on the usage of slow-moving system in Guangdong greenway from the perspective of news [J]. Landscape Architecture, 2019, 26 (01): 86-90.

Chen Keshi, Zhou Yanlu. Summary of Greenway Planning Practice in China under the Background of Urban-Rural Coordination [J]. Modern Urban Research, 2015 (5): 5157.

Kairan Li, Ecological Corridor Function and Planning Principles of Greenway Network, Chinese Gardens, 2010 (03): 24-27.

Zheng Liu. Urbanism Transition: Planning and Implementation of Greenway in Pearl River Delta [D]. South China University of Technology, 2017.

Ding Yan, Gong Yanan, Du Peishan, Chen Ye, Sun Feng and Guo Yiyan. A method of constructing urban-rural greenway network for Whole-region tourism: taking Dandong as an example [J]. Journal of Liaodong University (Natural Science Edition), 2018, 25 (03): 207-213.

Kong Qiang, Li Xiaolan. Rural Greenway Planning and Construction Strategy Guided by Whole-region Tourism [J/OL]. Anhui Agricultural Science, 2019 (03): 111-113 [201902-27].

Ergen, B., 2014. Euclidean distance mapping and the proposed greenway method in Malta. J. Urban Plann. Dev. 140.

Environmental Systems Research Institute (ESRI), I, 1994. Arc/Info Users Guide, Cellbased Modeling With GRID.

Yue Liu. Construction of Greenway Network in Dahexi Pilot Area of Changsha City based on GIS [D]. Hunan University, 2011.

Jing Q, Wei-Ning X, Yanfang $L$, et al. Incorporating landscape diversity into green way alignment planning [J]. Urban Forestry \& Urban Greening, 2018, 35:45-56.

Chandio, I.A., Matori, A.N., Lawal, D.U., Sabri, S., 2011. GIS-based land suitability analysis using AHP for public parks planning in Larkana City. Mod. Appl. Sci.5. 